\title{
Effect of breast-feeding on weight retention at 3 and 6 months postpartum: data from the North Carolina WIC Programme
}

\author{
Katrina M Krause ${ }^{1, *}$, Cheryl A Lovelady ${ }^{2}$, Bercedis L Peterson ${ }^{3}$, Najmul Chowdhury ${ }^{4}$ \\ and Truls Østbye ${ }^{1,5}$ \\ 'Department of Community and Family Medicine, Duke University Medical Center, PO Box 104006, Durham, \\ NC 27710, USA: ${ }^{2}$ Department of Nutrition, University of North Carolina at Greensboro, Greensboro, NC, \\ USA: ${ }^{3}$ Department of Biostatistics and Bioinformatics, Duke University Medical Center, Durham, NC, USA: \\ ${ }^{4}$ North Carolina Department of Health and Human Services, Nutrition Services Branch, Division of Public Health, \\ Rayleigh, NC, USA: ${ }^{5}$ Duke-NUS Graduate Medical School, Singapore, Singapore
}

Submitted 11 November 2009: Accepted 19 April 2010: First published online 2 June 2010

\begin{abstract}
Objective: Pregnancy-related weight retention can contribute to obesity, and breast-feeding may facilitate postpartum weight loss. We investigated the effect of breast-feeding on postpartum weight retention.

Design: A retrospective follow-up study of weight retention, compared in women who were fully breast-feeding, combining breast-feeding with formula-feeding (mixed feeding), or formula-feeding at 3 months ( $n$ 14330) or 6 months ( $n$ 4922) postpartum, controlling for demographic and weight-related covariates using multiple linear regression.

Setting: The North Carolina Special Supplemental Nutrition Program for Women, Infants, and Children (WIC).

Subjects: Participants in the North Carolina WIC Programme who delivered a baby between 1996 and 2004.

Results: In covariate-adjusted analyses, there was no association between breastfeeding and weight retention at 3 months postpartum. At 6 months postpartum, as compared to formula-feeders, mean weight retention was $0.84 \mathrm{~kg}$ lower in mixed feeders $(95 \%$ CI $0 \cdot 39,1 \cdot 29 ; P=0 \cdot 0002)$ and $1.38 \mathrm{~kg}$ lower in full breast-feeders (95\% CI $0 \cdot 89,1 \cdot 87 ; P \leq 0 \cdot 0001)$.

Conclusions: Breast-feeding was inversely associated with weight retention at 6 months postpartum in this large, racially diverse sample of low-income women. Further, full breast-feeding had a larger protective effect than did breast-feeding combined with formula-feeding.
\end{abstract}

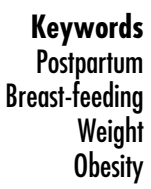

Keywords

Postpartum

Weight

Obesity
Postpartum weight retention can contribute to the development of obesity in women ${ }^{(1,2)}$. Given the breadth of negative health outcomes associated with obesity ${ }^{(3,4)}$ and its prevalence in the $\mathrm{USA}^{(5)}$, it is imperative that risk and protective factors for obesity be identified.

Postpartum weight retention is highly variable, but has been consistently associated with a small number of important risk factors including black race ${ }^{(6-8)}$, pre-pregnancy weight $^{(9)}$ and the amount of weight gained during pregnancy ${ }^{(10,11)}$. Protective factors are less well studied, but include modifiable behavioural strategies such as healthy diet and physical activity ${ }^{(12-15)}$ and mode of infant feeding.

Studies conducted across various populations have found a significant relationship between the duration of breast-feeding and postpartum weight change, particularly when breast-feeding continued for at least 6 months ${ }^{(16-20)}$. Other studies report the effect of breast-feeding on postpartum weight loss to be absent ${ }^{(21)}$ or minimal and easily confounded $^{(22-23)}$, leading some to characterize the evidence of a relationship as being mixed or inconclusive ${ }^{(24-26)}$. One reason for this variation in findings may be that the effect of breast-feeding can be attenuated by excessive energy intake $^{(27)}$. It may also be that breast-feeding must be sustained for a minimum period before a significant impact on weight loss can be realized ${ }^{(16,17)}$.

The objective of the present analyses was to determine the effect of breast-feeding on weight retention at 3 and 6 months postpartum in a large, racially diverse cohort, adjusting for important demographic and weight-related covariates.

\section{Methods}

\section{Data}

We investigated the relationship between breast-feeding and postpartum weight retention in women who participated 


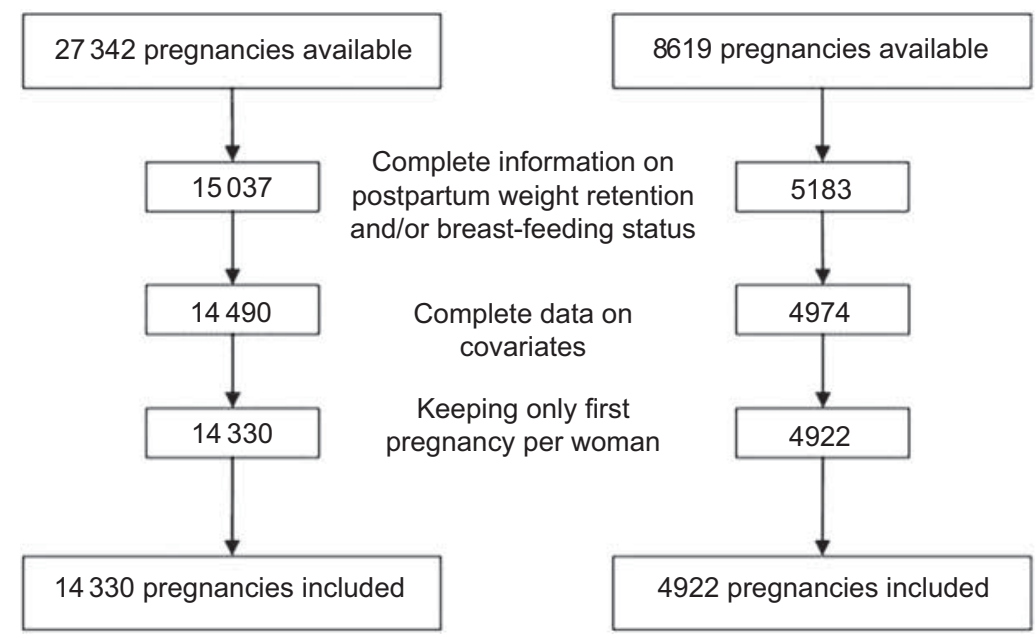

Fig. 1 Samples used in statistical analysis

in the Special Supplemental Nutrition Program for Women, Infants, and Children (WIC) in North Carolina. The WIC Programme provides vouchers for food and beverages, education about nutrition and health-care referrals to low-income pregnant women, non-breast-feeding postpartum women (up to 6 months after the birth of an infant), and breast-feeding women (up to the infant's first birthday), as well as their children up to the age of 5 years. Data including height and weight are collected when women are admitted to the WIC Programme during pregnancy, and at the postpartum recertification visit, when the mother renews her participation in WIC after giving birth.

North Carolina's Pregnancy Nutrition Surveillance System (NC PNSS) is compiled by linking data from the WIC Programme with birth certificates and fetal death certificates. The data used in the present study were collected through the NC PNSS, and include variables from the WIC prenatal and postpartum clinic visits and from the birth certificate (including delivery date and mother's demographic data). Data from all pregnancies in the NC PNSS from 1996 to 2004, which had been de-identified with the exception of a coded WIC participant identification number, were obtained through a data use agreement for these analyses. This agreement and the study protocol were approved by the Duke University Institutional Review Board.

The paper presents a retrospective follow-up study of postpartum weight retention in women recertifying in the WIC Programme at 3 (60-90 d) and 6 (150-180 d) months postpartum. We removed records with missing data and, since there were some women with multiple pregnancies in the data set, selected only one pregnancy per woman to use in the analysis. As shown in Fig. 1, these steps resulted in final sample sizes of 14330 and 4922 women at 3 and 6 months postpartum, respectively.

\section{Measures}

\section{Postpartum weight retention}

Postpartum weight (in pounds) for each woman was measured at the WIC postpartum recertification visit. Selfreported pre-pregnancy weight (in pounds) was collected at the WIC prenatal visit. The outcome for these analyses, postpartum weight retention, was derived by subtracting the self-reported pre-pregnancy weight from the measured postpartum weight. Acceptable ranges for weight (80-600 lbs) and postpartum weight retention ( -75 to $100 \mathrm{lbs}$ ) were established based on distributions within the study samples. All weight-related variables were converted to kilograms for final analyses.

\section{Breast-feeding}

Three separate questions assessed breast-feeding status at the time of the postpartum visit: current breast-feeding (yes/ no), when breast-feeding was discontinued (age of infant in weeks), and when formula was first introduced (age of infant in weeks). To be categorized in the 'full breast-feeding' group, women had to answer that they were currently breast-feeding, had never discontinued breast-feeding, and had never introduced formula. Women categorized as 'mixed feeding' (combining breast-feeding with formulafeeding) responded that they were currently breast-feeding, had not discontinued breast-feeding, but had introduced formula. To be categorized as 'formula-feeding', women had to report that they were not currently breast-feeding, had discontinued breast-feeding before the time of the visit and had introduced formula before the time of the visit.

\section{Covariate measures}

We adjusted for seven covariates related to breast-feeding or weight retention in assessing the association between 
the two. These included the woman's age (range: 12-49 years), race, ethnicity (Hispanic; yes/no), education (range: $0-17$ years), parity (range: $1-8$ ), gestational weight gain and pre-pregnancy BMI $\left(\mathrm{kg} / \mathrm{m}^{2}\right)$. Height was needed to derive the pre-pregnancy BMI; if the measured height at the postpartum recertification visit was missing or out of range (48-72 in), a prenatal measure was used (if available and in range). Given its high correlation (0.944) with pre-pregnancy weight, pre-pregnancy BMI also served as the baseline control value of the outcome in the multivariable model.

\section{Statistical analysis}

The general linear model was used to test the association of weight retention with breast-feeding at 3 and 6 months, controlling for the covariates listed above. Breast-feeding was tested with two separate contrasts, i.e. full breast-feeding $v$. formula only; and mixed feeding $v$. formula only. Race was categorized as black $v$. non-black, after determining the goodness-of-fit of this dichotomy. All categorical variables were modelled with reference cell coding. Continuous variables were modelled as linear unless their quadratic terms were significant; thus, $P$ values for continuous variables may have either 1 or $2 \mathrm{df}$ (cubic terms were also tested, but none was statistically significant). All covariates were included in the multivariate model, regardless of $P$ value, as recommended by Harrell ${ }^{(28)}$. Postpartum weight retention was well approximated by normal distribution.

Means with their standard errors on weight retention are presented according to breast-feeding status and levels of the covariates, where, for the purpose of presentation, continuous covariates are categorized at clinically meaningful cutpoints. Pre-pregnancy BMI was categorized according to the National Heart, Lung and Blood Institute guidelines $^{(29)}$, and gestational weight gain according to the recommendations of the Institute of Medicine ${ }^{(30)}$. Covariateadjusted effects are presented as regression coefficients from the multivariate regression model. Regression coefficients for dichotomous predictors are equal to the covariateadjusted mean difference in weight retention between the two categories. Regression coefficients for continuous predictors include a linear term and possibly a quadratic term. The quadratic terms, while significant, forced only very slight curvatures away from linearity. Therefore, all linear terms can be thought of as being equal to (or a very good approximation of) the change in mean weight retention for a one-unit increase in the covariate. All statistical tests used a two-sided $\alpha$ of $0 \cdot 01$. Statistical analysis was performed using the SAS statistical software package version $8 \cdot 2$ (SAS Institute, Cary, NC, USA).

\section{Results}

When comparing women included in the analysis to those excluded, the women excluded at 3 months were more likely to be older, white, Hispanic and more educated; they had fewer children and gained less weight during pregnancy. At 6 months, only white women and those with lower gestational weight gain were more likely to be excluded. In general, these differences were small and assumed to be clinically unimportant with the exception of race; at both time points, black women were more likely to have complete data than whites and other races.

Characteristics of the WIC participants who were included in the 3 and 6 months postpartum analysis samples are presented in Table 1 . In the 3-month sample, $7 \%$ of women were fully breast-feeding and $16 \%$ were mixed feeding. In the 6-month sample, $25 \%$ were fully breast-feeding, whereas $47 \%$ were mixed feeding. The rates of breast-feeding at this time point appear higher because women who are formula-feeding may receive WIC benefits only up to 6 months postpartum. As this deadline approaches, fewer formula-feeding women are recertifying and the proportion of breast-feeders is high. As a result, the 6-month group was slightly older, and had a greater proportion of whites and Hispanics. They were more likely to have three or more older children in addition to the current newborn, and also more likely to have some college education. In the 3 -month sample, $16 \%$ of births were preterm and $2 \%$ were multiple gestation; in the 6 -month sample, $8 \%$ of births were preterm and $1 \%$ was multiple gestation (data not shown). Mean postpartum weight retention was 5.3 (SD 6.9$) \mathrm{kg}$ in the 3-month postpartum sample and $5 \cdot 6$ (sD 7.0) $\mathrm{kg}$ in the 6-month postpartum sample (data not shown).

Means on weight retention according to levels of the covariates, including breast-feeding, are presented in Table 2 . Weight retention did not differ by breast-feeding status at 3 months. At 6 months, mean weight retention in mixed feeders was $1.6 \mathrm{~kg}$ lower than in formula-feeders, and $1.8 \mathrm{~kg}$ lower in full breast-feeders. At both time points, mothers who were older, more educated and had more children retained less weight. Hispanic women retained less weight than non-Hispanics, while results differed for black women at 3 and 6 months postpartum. Women with greater gestational weight gain retained more weight at both time points, while increased prepregnancy BMI was associated with reduced postpartum weight retention.

The effect of breast-feeding status on weight retention at each time point, controlling for covariates, is presented in Table 3. At 3 months postpartum, there was no association between breast-feeding and weight retention. At 6 months postpartum, as compared to formula-feeders, mean weight retention was $0.84 \mathrm{~kg}$ lower among mixed feeders (95\% CI 0.39, $1 \cdot 29 ; P=0.0002)$ and $1.38 \mathrm{~kg}$ lower among full breast-feeders (95\% CI 0.89, 1.87; $P<0 \cdot 0001)$. In addition, at 6 months postpartum, women with more education retained less weight $(0 \cdot 14 \mathrm{~kg} /$ year of education; $P=0.0002)$ and black women retained $1.33 \mathrm{~kg}$ more than women of other races $(P<0 \cdot 0001)$. Weight gain during 
Table 1 Description of WIC samples from 1996 to 2004

\begin{tabular}{|c|c|c|c|c|}
\hline \multirow[b]{2}{*}{ Variable } & \multicolumn{2}{|c|}{$\begin{array}{l}\text { Analysis sample at } 3 \text { months postpartum } \\
\qquad(n 14330)\end{array}$} & \multicolumn{2}{|c|}{$\begin{array}{l}\text { Analysis sample at } 6 \text { months postpartum } \\
\text { ( } n \text { 4922) }\end{array}$} \\
\hline & $n$ (or mean) & $\%$ (or SD) & $n$ (or mean) & $\%$ (or SD) \\
\hline \multicolumn{5}{|l|}{ Breast-feeding initiation } \\
\hline Never breast-fed & 7100 & $49 \cdot 6$ & 898 & $18 \cdot 2$ \\
\hline Ever breast-fed & 7230 & $50 \cdot 4$ & 4024 & $81 \cdot 8$ \\
\hline \multicolumn{5}{|l|}{ Breast-feeding status } \\
\hline Formula-feeding & 11024 & $76 \cdot 9$ & 1360 & $27 \cdot 6$ \\
\hline Mixed feeding & 2304 & $16 \cdot 1$ & 2334 & $47 \cdot 4$ \\
\hline Full breast-feeding & 1002 & $7 \cdot 0$ & 1228 & $25 \cdot 0$ \\
\hline \multicolumn{5}{|l|}{ Covariates } \\
\hline Age (years) & $23 \cdot 5^{\star}$ & $5 \cdot 5^{\star}$ & $25 \cdot 2^{*}$ & $5 \cdot 6^{\star}$ \\
\hline$<18$ & 1421 & $9 \cdot 9$ & 268 & $5 \cdot 4$ \\
\hline $18-24$ & 7773 & $54 \cdot 2$ & 2275 & $46 \cdot 2$ \\
\hline $25-34$ & 4432 & $30 \cdot 9$ & 2018 & $41 \cdot 0$ \\
\hline$\geq 35$ & 704 & $4 \cdot 9$ & 361 & $7 \cdot 3$ \\
\hline \multicolumn{5}{|l|}{ Race } \\
\hline White & 8082 & $56 \cdot 4$ & 3280 & $66 \cdot 6$ \\
\hline Black & 5803 & $40 \cdot 5$ & 1475 & $30 \cdot 0$ \\
\hline Other races & 445 & $3 \cdot 1$ & 167 & $3 \cdot 4$ \\
\hline \multicolumn{5}{|l|}{ Ethnicity } \\
\hline Hispanic & 1761 & $12 \cdot 3$ & 1258 & $25 \cdot 6$ \\
\hline Non-Hispanic & 12569 & $87 \cdot 7$ & 3664 & $74 \cdot 4$ \\
\hline Education (years) & $11 \cdot 4^{*}$ & $2 \cdot 2^{*}$ & $11 \cdot 5^{\star}$ & $2 \cdot 9^{*}$ \\
\hline Less than high school & 5396 & $37 \cdot 7$ & 1706 & $34 \cdot 7$ \\
\hline High school graduate & 5781 & $40 \cdot 3$ & 1805 & $36 \cdot 7$ \\
\hline Some college & 2614 & $18 \cdot 2$ & 1034 & $21 \cdot 0$ \\
\hline College graduate & 539 & $3 \cdot 8$ & 377 & $7 \cdot 7$ \\
\hline \multicolumn{5}{|l|}{ Number of live births } \\
\hline 1 & 6565 & $45 \cdot 8$ & 1890 & $38 \cdot 4$ \\
\hline 2 & 4269 & $29 \cdot 8$ & 1557 & $31 \cdot 6$ \\
\hline $3+$ & 3496 & $24 \cdot 4$ & 1475 & $30 \cdot 0$ \\
\hline Pre-pregnancy BMI (kg/m²) & $26 \cdot 3^{*}$ & $7 \cdot 0^{\star}$ & $26 \cdot 4^{*}$ & $6 \cdot 5^{\star}$ \\
\hline Underweight $^{(29)}(<18.5)^{\prime}$ & 953 & $6 \cdot 7$ & 255 & $5 \cdot 2$ \\
\hline Normal weight $(18 \cdot 5-24 \cdot 9)$ & 6574 & $45 \cdot 9$ & 2225 & $45 \cdot 2$ \\
\hline Overweight $(25 \cdot 0-29 \cdot 9)$ & 3319 & $23 \cdot 2$ & 1229 & $25 \cdot 0$ \\
\hline Obese class I (30.0-34.9) & 1852 & $12 \cdot 9$ & 716 & $14 \cdot 6$ \\
\hline Obese class II (35.0-39.9) & 921 & $6 \cdot 4$ & 291 & $5 \cdot 9$ \\
\hline Obese class III $(\geq 40 \cdot 0)$ & 711 & $5 \cdot 0$ & 206 & $4 \cdot 2$ \\
\hline Weight gain during pregnancy $(\mathrm{kg})$ & $13 \cdot 6^{\star}$ & $6 \cdot 7^{\star}$ & $13 \cdot 5^{\star}$ & $6 \cdot 5^{\star}$ \\
\hline Below IOM recommendations ${ }^{(30)}$ & 4160 & $29 \cdot 0$ & 1410 & $28 \cdot 7$ \\
\hline Within IOM recommendations & 4620 & $32 \cdot 2$ & 1652 & $33 \cdot 6$ \\
\hline Above IOM recommendations & 5550 & $38 \cdot 7$ & 1860 & $37 \cdot 8$ \\
\hline
\end{tabular}

WIC, The North Carolina Special Supplemental Nutrition Program for Women, Infants, and Children; IOM, Institute of Medicine.

*Data are presented as mean and SD.

pregnancy had the largest effect of any variable in the models, with women retaining about half of every kilogram gained during pregnancy at both time points $(P<0 \cdot 0001)$. Increased pre-pregnancy BMI was negatively correlated with postpartum weight retention.

\section{Discussion}

In this large, racially diverse sample of low-income women, breast-feeding status had no effect on weight retention at 3 months postpartum but had a significant effect at 6 months postpartum. At this later time point, full breastfeeding conferred a greater benefit than did mixed feeding, indicating that the amount of breast-feeding is inversely correlated with weight retention in the postpartum period.
Nevertheless, both mixed and full breast-feeding resulted in greater postpartum weight loss when compared to formula-feeding.

Our differing results at 3 and 6 months postpartum are congruent with previous findings ${ }^{(31)}$. In a study of 1423 Swedish women over the first postpartum year, Ohlin and Rossner ${ }^{(16)}$ found that the impact of breast-feeding was greatest between $2 \cdot 5$ and 6 months after delivery. Dewey et $a l .{ }^{(17)}$ followed forty-six breast-feeding and thirty-nine formula-feeding women for 2 years, and similarly found no difference in weight loss between the groups from 1 to 3 months, but a significant difference from 3 to 6 months postpartum. Although some other studies have presented data on the effect of weight loss at more than one time point up to 18 months postpartum ${ }^{(19-20,22)}$, few quantify the impact of breast-feeding duration before 6 months 
Table 2 Mean weight retention according to the levels of the predictor variables at 3 and 6 months postpartum

\begin{tabular}{|c|c|c|c|c|}
\hline \multirow[b]{2}{*}{ Variable } & \multicolumn{2}{|c|}{$\begin{array}{l}\text { Weight retention at } 3 \text { months postpartum } \\
\qquad(\mathrm{kg} ; n \text { 14 330) }\end{array}$} & \multicolumn{2}{|c|}{$\begin{array}{l}\text { Weight retention at } 6 \text { months postpartum } \\
(\mathrm{kg} ; n \text { 4922) }\end{array}$} \\
\hline & Mean & SE & Mean & SE \\
\hline \multicolumn{5}{|l|}{ Breast-feeding status } \\
\hline Formula-feeding & $5 \cdot 3$ & 0.07 & $6 \cdot 8$ & $0 \cdot 20$ \\
\hline Mixed feeding & $5 \cdot 2$ & $0 \cdot 13$ & $5 \cdot 2$ & $0 \cdot 14$ \\
\hline Full breast-feeding & $5 \cdot 2$ & $0 \cdot 20$ & $5 \cdot 0$ & $0 \cdot 19$ \\
\hline \multicolumn{5}{|l|}{ Covariates } \\
\hline \multicolumn{5}{|l|}{ Age (years) } \\
\hline$<18$ & $6 \cdot 6$ & $0 \cdot 18$ & $7 \cdot 2$ & $0 \cdot 45$ \\
\hline $18-24$ & $5 \cdot 7$ & 0.08 & $6 \cdot 1$ & $0 \cdot 15$ \\
\hline $25-34$ & $4 \cdot 5$ & $0 \cdot 11$ & $5 \cdot 1$ & $0 \cdot 15$ \\
\hline$\geq 35$ & $4 \cdot 0$ & 0.26 & $4 \cdot 3$ & 0.33 \\
\hline \multicolumn{5}{|l|}{ Race } \\
\hline White & $5 \cdot 6$ & 0.07 & $5 \cdot 4$ & $0 \cdot 11$ \\
\hline Black & $4 \cdot 9$ & 0.09 & $6 \cdot 2$ & 0.20 \\
\hline \multicolumn{5}{|l|}{ Ethnicity } \\
\hline Non-Hispanic & $5 \cdot 4$ & 0.06 & $5 \cdot 8$ & $0 \cdot 12$ \\
\hline Hispanic & 4.9 & $0 \cdot 14$ & $5 \cdot 1$ & $0 \cdot 17$ \\
\hline \multicolumn{5}{|l|}{ Education } \\
\hline Not a high school graduate & $5 \cdot 4$ & 0.09 & $5 \cdot 9$ & $0 \cdot 16$ \\
\hline High school graduate & $5 \cdot 3$ & 0.09 & $5 \cdot 6$ & $0 \cdot 17$ \\
\hline Some college & $5 \cdot 3$ & $0 \cdot 14$ & $5 \cdot 4$ & $0 \cdot 22$ \\
\hline College graduate or more & 4.9 & 0.27 & $4 \cdot 8$ & $0 \cdot 32$ \\
\hline \multicolumn{5}{|l|}{ Number of live births } \\
\hline 1 & $6 \cdot 2$ & 0.08 & $6 \cdot 5$ & $0 \cdot 17$ \\
\hline 2 & $4 \cdot 8$ & $0 \cdot 10$ & $5 \cdot 1$ & $0 \cdot 17$ \\
\hline $3+$ & $4 \cdot 2$ & 0.12 & $5 \cdot 0$ & $0 \cdot 18$ \\
\hline \multicolumn{5}{|l|}{ Pre-pregnancy BMI $\left(\mathrm{kg} / \mathrm{m}^{2}\right)$} \\
\hline Underweight $^{(29)}(<18 \cdot 5)$ & $6 \cdot 6$ & $0 \cdot 18$ & $6 \cdot 7$ & 0.35 \\
\hline Normal weight $(18 \cdot 5-24 \cdot 9)$ & $6 \cdot 5$ & 0.07 & $6 \cdot 7$ & $0 \cdot 13$ \\
\hline Overweight $(25 \cdot 0-29 \cdot 9)$ & $5 \cdot 4$ & $0 \cdot 12$ & $5 \cdot 5$ & $0 \cdot 19$ \\
\hline Obese class I (30.0-34.9) & $3 \cdot 9$ & $0 \cdot 18$ & $4 \cdot 1$ & $0 \cdot 28$ \\
\hline Obese class II (35.0-39.9) & $2 \cdot 2$ & 0.26 & $3 \cdot 5$ & 0.46 \\
\hline Obese class III ( $\geq 40 \cdot 0)$ & $-0 \cdot 3$ & 0.32 & $1 \cdot 4$ & $0 \cdot 70$ \\
\hline \multicolumn{5}{|l|}{ Weight gain during pregnancy } \\
\hline Below IOM recommendations ${ }^{(30)}$ & $2 \cdot 0$ & $0 \cdot 10$ & $3 \cdot 0$ & $0 \cdot 17$ \\
\hline Within IOM recommendations & $4 \cdot 6$ & 0.08 & $5 \cdot 0$ & $0 \cdot 14$ \\
\hline Above IOM recommendations & $8 \cdot 3$ & $0 \cdot 10$ & $8 \cdot 2$ & $0 \cdot 17$ \\
\hline
\end{tabular}

IOM, Institute of Medicine.

Table 3 Predictors of weight retention at 3 and 6 months postpartum; multivariable linear regression

\begin{tabular}{|c|c|c|c|c|c|c|}
\hline \multirow[b]{2}{*}{ Variable } & \multicolumn{2}{|c|}{$\begin{array}{l}\text { Weight retention at } 3 \text { months } \\
\text { postpartum (kg; } n \text { 14330) }\end{array}$} & \multirow[b]{2}{*}{$P$ value } & \multicolumn{2}{|c|}{$\begin{array}{l}\text { Weight retention at } 6 \text { months } \\
\text { postpartum }(\mathrm{kg} ; n \text { 4922) }\end{array}$} & \multirow[b]{2}{*}{$P$ value } \\
\hline & Regression coefficient & SE & & Regression coefficient & SE & \\
\hline \multicolumn{7}{|l|}{ Breast-feeding status* } \\
\hline Mixed feeding & $0 \cdot 18$ & $0 \cdot 14$ & $0 \cdot 21$ & -0.84 & 0.23 & 0.0002 \\
\hline Full breast-feeding & -0.33 & $0 \cdot 19$ & 0.09 & $-1 \cdot 38$ & 0.25 & $<0.0001$ \\
\hline \multicolumn{7}{|l|}{ Covariates } \\
\hline Age (years) & -0.02 & 0.01 & 0.03 & -0.04 & 0.02 & 0.06 \\
\hline Black racet & $0 \cdot 20$ & $0 \cdot 10$ & 0.06 & $1 \cdot 33$ & $0 \cdot 21$ & $<0.0001$ \\
\hline Hispanic ethnicitył & 0.33 & $0 \cdot 17$ & 0.06 & 0.35 & $0 \cdot 26$ & 0.18 \\
\hline Education (years) & -0.003 & 0.02 & 0.91 & -0.14 & 0.04 & 0.0002 \\
\hline Number of live births & -0.004 & 0.05 & 0.93 & $0 \cdot 17$ & 0.09 & 0.05 \\
\hline \multicolumn{7}{|c|}{ Pre-pregnancy BMI $\left(\mathrm{kg} / \mathrm{m}^{2}\right)$} \\
\hline Linear & $-0 \cdot 14$ & 0.01 & $<0.0001(2) \S$ & $-0 \cdot 10$ & 0.02 & $<0.0001(2)$ \\
\hline Quadratic & -0.004 & 0.00 & & -0.005 & 0.00 & \\
\hline \multicolumn{7}{|c|}{ Weight gain during pregnancy $(\mathrm{kg})$} \\
\hline Linear & 0.51 & 0.01 & $<0.0001(2)$ & 0.45 & 0.01 & $<0.0001(2)$ \\
\hline
\end{tabular}

*Reference category: formula-feeding.

tReference category: all other races.

‡Reference category: non-Hispanic.

$\S$ Variables with a corresponding quadratic term (2 df test) noted in parentheses as (2). 
after delivery. Our results are consistent with those of Ohlin and Rossner ${ }^{(16)}$ and of Dewey et $a l^{(17)}$, but in a much larger and racially diverse cohort.

Further, despite the sizeable effects of such measures as race, education, pre-pregnancy BMI and gestational weight gain, the effect of breast-feeding at 6 months postpartum remained after controlling for these variables. Together with the studies discussed above, as well as the recent report by Baker et al. ${ }^{(20)}$ (which showed a significant effect of breast-feeding on weight retention at 6 months postpartum in a large cohort of Danish women), our results support the hypothesis that there is an independent effect of breast-feeding on postpartum weight loss if breast-feeding is continued for at least 6 months.

The fact that we observed an association between breast-feeding and weight loss at 6 months and not at 3 months postpartum may indicate that a certain breastfeeding duration is necessary for the maximal effect to be observed. The average energy cost of lactation is $2092 \mathrm{~kJ}$ $(500 \mathrm{kcal}) / \mathrm{d}$; therefore, the greater energy deficit experienced with $6 v .3$ months of lactation likely contributed to the different results at each time point. In addition, Lof and Forsum ${ }^{(32)}$ showed that expansion of plasma volume during pregnancy can persist during at least the first month postpartum. They measured body water in healthy women before, during and after pregnancy and reported an average of $2 \mathrm{~kg}$ of fluid remaining at 2 weeks postpartum. It is plausible that such physiological after-effects of pregnancy may mask differences in weight loss between lactating and formula-feeding women in the early postpartum period.

The strengths of the present study include a large, racially diverse sample, and the availability of important control measures such as race, pre-pregnancy BMI and gestational weight gain. Its limitations include the fact that the measures at 3 and 6 months were not collected serially from the same individuals, but from separate groups of women recertifying at each time point, which must be taken into consideration when interpreting the results reported and when making comparisons with other studies. The women in the present study were all lowincome participants in the WIC Programme; while this limits generalizability to the general population, it does reasonably represent low-income women in the Southern USA, a group that is at higher risk for obesity and that has lower rates of breast-feeding. Lower proportions of formula-feeders were likely to recertify as late as 6 months postpartum, and case loss due to missing data was also a limitation. Finally, the relationship between pre-pregnancy BMI and postpartum weight loss may have differed at later time points, had they been available. Baker et al. ${ }^{(20)}$ found in their sample, as in the current study, that pre-pregnancy BMI was negatively associated with weight retention at 6 months postpartum. However, Gunderson et $a l .{ }^{(9)}$ noted that early postpartum weight loss in their sample did not vary by pre-pregnancy BMI, but that late postpartum weight change (i.e. a median of 2 years after delivery) did.

The positive health effects of breast-feeding for the newborn have been well established ${ }^{(33)}$. Breast-feeding can also be beneficial to the mother's health, including reduced risks of type 2 diabetes, ovarian cancer and breast cancer $^{(26)}$. These benefits have made the promotion of breast-feeding a Healthy People $2010^{(34)}$ priority as well as a major component of the WIC educational programme ${ }^{(35)}$. Our results suggest that breast-feeding can also effect modest reductions in postpartum weight retention, adding to its overall benefits to the mother and child.

Earlier reports indicate a lower rate of breast-feeding among WIC participants than in the general population $^{(36-38)}$. Encouraging breast-feeding is especially important in low-income women, who are disproportionately affected by obesity and related health problems that may be positively impacted by breast-feeding. Studies of WIC groups suggest that participants are aware of the health benefits of breast-feeding for their infants, and that structural barriers such as return to work are less of a problem than attitudinal barriers, including embarrassment about public feeding, the perception of breast-feeding as limiting or inconvenient, and fears of inadequate supply ${ }^{(38)}$. Such attitudes are amenable to intervention and education, and WIC Programmes designed to educate participants and provide peer-counselling support services have shown that they can positively impact breast-feeding in this population ${ }^{(39-41)}$.

Further, implementation of a new WIC food package design, effective from 1 October 2009, is an important step forward in breast-feeding promotion efforts in this population. This change is the result of an Institute of Medicine review of the WIC Programme food packages and addresses concerns that formula supplementation available through WIC may have the unintended effect of de-incentivizing breast-feeding in this population ${ }^{(42)}$. The new food packages align with the 2005 Dietary Guidelines for Americans and infant feeding practice guidelines of the American Academy of Pediatrics, and are designed to better promote and support the establishment of successful long-term breast-feeding. Such efforts are widely supported and have the potential to impact perceptions about breast-feeding and formula supplementation among WIC participants ${ }^{(43)}$. Given that up to half of all infants in the USA participate in WIC $^{(36)}$, encouraging breast-feeding in this population could benefit the overall health of a substantial proportion of American women and children.

\section{Conclusion}

In this large, racially diverse sample of low-income women participating in the WIC Programme, breast-feeding was associated with reduced weight retention at 6 months postpartum, controlling for important demographic and weight-related covariates. 


\section{Acknowledgements}

The present study received no specific grant from any funding agency in the public, commercial or not-forprofit sectors. The authors have no conflicts of interest to disclose. K.M.K. conducted the analyses and wrote the manuscript. C.A.L. conceived the study and acquired the data. T. $\varnothing$. and C.A.L. participated in designing the study and assisted in analysing the data and editing the manuscript. B.L.P. assisted in statistical design, analysis and reporting. N.C. provided consultation on data and reviewed the analysis and manuscript for completeness and accuracy. The authors thank Alice Lenihan, RD, MPH, LDN, Branch Head of Nutrition Services Branch, NC DHHS, for facilitating access to the data used in the present study report. They also thank Dr Sara Benjamin for her helpful suggestions.

\section{References}

1. Gunderson EP \& Abrams B (1999) Epidemiology of gestational weight gain and body weight changes after pregnancy. Epidemiol Rev 21, 261-275.

2. Gore SA, Brown DM \& West DS (2003) The role of postpartum weight retention in obesity among women: a review of the evidence. Ann Behav Med 26, 149-159.

3. Must A, Spadano J, Coakley EH et al. (1999) The disease burden associated with overweight and obesity. JAMA $\mathbf{2 8 2}$, 1523-1529.

4. Calle EE, Rodriguez C, Walker-Thurmond K et al. (2003) Overweight, obesity, and mortality from cancer in a prospectively studied cohort of US adults. $N$ Engl $\mathrm{J} \mathrm{Med}$ 348, 1625-1638.

5. Ogden CL, Carroll MD, Curtin LR et al. (2006) Prevalence of overweight and obesity in the United States, 1999-2004. JAMA 295, 1549-1555.

6. Parker JD \& Abrams B (1993) Differences in postpartum weight retention between black and white mothers. Obstet Gynecol 81, 768-774.

7. Boardley DJ, Sargent RG, Coker AL et al. (1995) The relationship between diet, activity, and other factors, and postpartum weight change by race. Obstet Gynecol 86, 834-838.

8. Smith DE, Lewis CE, Caveny JL et al. (1994) Longitudinal changes in adiposity associated with pregnancy - the CARDIA study. JAMA 271, 1747-1751.

9. Gunderson EP, Abrams B \& Selvin S (2001) Does the pattern of postpartum weight change differ according to pregravid body size? Int J Obes 25, 853-862.

10. Viswanathan M, Siega-Riz AM, Moos M-K et al. (2008) Outcomes of Maternal Weight Gain, Evidence Report/ Technology Assessment no. 168. (Prepared by RTI International University of North Carolina Evidence-based Practice Center under contract no. 290-02-0016.) AHRQ Publication no. 08-E-09. Rockville, MD: Agency for Healthcare Research and Quality.

11. Rooney BL \& Schauberger CW (2002) Excess pregnancy weight gain and long-term obesity: one decade later. Obstet Gynecol 100, 245-252.

12. Amorim AR, Linne YM \& Lourenco PM (2007) Diet or exercise, or both, for weight reduction in women after childbirth. Cochrane Database Syst Rev issue 3, CD005627.

13. Oken E, Taveras EM, Popoola FA et al. (2007) Television, walking, and diet: associations with postpartum weight retention. Am J Prev Med 32, 305-311.
14. Olson CM, Strawderman MS, Hinton PS et al. (2003) Gestational weight gain and postpartum behaviors associated with weight change from early pregnancy to $1 \mathrm{y}$ postpartum. Int J Obes Relat Metab Disord 27, 117-127.

15. Ohlin A \& Rossner S (1994) Trends in eating patterns, physical activity and socio-demographic factors in relation to postpartum body weight development. Br J Nutr 71, 457-470.

16. Ohlin A \& Rössner S (1990) Maternal body weight development after pregnancy. Int J Obes 14, 159-173.

17. Dewey KG, Heinig MJ \& Nommsen LA (1993) Maternal weight-loss patterns during prolonged lactation. Am J Clin Nutr 58, 162-166.

18. Dewey KG, Cohen RJ, Brown KH et al. (2001) Effects of exclusive breastfeeding for four versus six months on maternal nutritional status and infant motor development: results of two randomized trials in Honduras. J Nutr $\mathbf{1 3 1}$, 262-267.

19. Kac G, Benício MH, Velásquez-Meléndez G et al. (2004) Breastfeeding and postpartum weight retention in a cohort of Brazilian women. Am J Clin Nutr 79, 487-493.

20. Baker JL, Gamborg M, Heitmann BL et al. (2008) Breastfeeding reduces postpartum weight retention. Am J Clin Nutr 88, 1543-1551.

21. Dugdale AE \& Eaton-Evans J (1989) The effect of lactation and other factors on post-partum changes in body-weight and triceps skinfold thickness. Br J Nutr 61, 149-153.

22. Janney CA, Zhang D \& Sowers M (1997) Lactation and weight retention. Am J Clin Nutr 66, 1116-1124.

23. Gigante DP, Victora CG \& Barros FC (2001) Breast-feeding has a limited long-term effect on anthropometry and body composition of Brazilian mothers. J Nutr 131, 78-84.

24. Butte NF \& Hopkinson JM (1998) Body composition changes during lactation are highly variable among women. J Nutr 128, Suppl. 2, 381S-385S.

25. Brewer MM, Bates MR \& Vannoy LP (1989) Postpartum changes in maternal weight and body fat depots in lactating vs nonlactating women. Am J Clin Nutr 49, 259-265.

26. Ip S, Chung M, Raman G et al. (2007) Breastfeeding and maternal and infant health outcomes in developed countries. Evid Rep Technol Assess (Full Rep) 153, 1-186.

27. Winkvist A \& Rasmussen KM (1999) Impact of lactation on maternal body weight and body composition. J Mammary Gland Biol Neoplasia 4, 309-318.

28. Harrell FE (2001) Regression Modelling Strategies with Applications to Linear Models, Logistic Regression, and Survival Analysis. New York: Springer.

29. National Heart, Lung and Blood Institute (1998) Obesity Education Initiative Expert Panel. Clinical Guidelines on the Identification, Evaluation, and Treatment of Overweight and Obesity in Adults. NIH Publication no. 98-4083. Bethesda, MD: National Institutes of Health.

30. Institute of Medicine (2009) Weight Gain during Pregnancy: Reexamining the Guidelines. Washington, DC: National Academies Press.

31. Dewey KG (2004) Impact of breastfeeding on maternal nutritional status. Adv Exp Med Biol 554, 91-100.

32. Lof M \& Forsum E (2004) Evaluation of bioimpedance spectroscopy for measurements of body water distribution in healthy women before, during, and after pregnancy. J Appl Physiol 96, 967-973.

33. American Academy of Pediatrics (AAP) Work Group on Breastfeeding (1997) Breastfeeding and the use of human milk. Pediatrics 100, 1035-1039.

34. US Department of Health and Human Services (2000) Healthy People 2010: Understanding and Improving Health, 2nd ed. Washington, DC: US Government Printing Office.

35. US Department of Agriculture, Food and Nutrition Service (2009) Benefits and services: breastfeeding promotion and support in WIC. http://www.fns.usda.gov/wic/Breastfeeding/ breastfeedingmainpage.HTM (accessed November 2009). 
36. Ryan AS \& Zhou W (2006) Lower breastfeeding rates persist among the Special Supplemental Nutrition Program for Women, Infants, and Children participants, 1978-2003. Pediatrics 117, 1136-1146.

37. Li R, Darling N, Maurice E et al. (2005) Breastfeeding rates in the United States by characteristics of the child, mother, or family: the 2002 National Immunization Survey. Pediatrics 115, e31-e37.

38. McCann MF, Baydar N \& Williams RL (2007) Breastfeeding attitudes and reported problems in a national sample of WIC participants. J Hum Lact 23, 314-324.

39. Ahluwalia IB, Tessaro I, Grummer-Strawn LM et al. (2000) Georgia's breastfeeding promotion program for lowincome women. Pediatrics 105, E85.
40. Finch C \& Daniel EL (2002) Breastfeeding education program with incentives increases exclusive breastfeeding among urban WIC participants. J Am Diet Assoc 102, 981-984.

41. Gross SM, Resnik AK, Cross-Barnet C et al. (2009) The differential impact of WIC peer counseling programs on breastfeeding initiation across the state of Maryland. J Hum Lact 25, 435-443.

42. Institute of Medicine (2005) WIC Food Packages: Time for a Change. Washington, DC: National Academies Press.

43. Holmes AV, Chin NP, Kaczorowski J et al. (2009) A barrier to exclusive breastfeeding for WIC enrollees: limited use of exclusive breastfeeding food package for mothers. Breastfeed Med 4, 25-30. 